\title{
Ação antimicrobiana do fator de crescimento epidérmico em feridas: revisão integrativa
}

\section{Antimicrobial action of epidermal growth factor in wounds: integrative review}

\author{
Fernanda Pessanha de Oliveira ${ }^{1}$ - Miriam Marinho Chrizóstimo² • Bruna Maiara Ferreira Barreto ${ }^{3}$ Euzeli da Silva \\ Brandão $^{4}$ • Ana Karine Ramos Brum ${ }^{5}$ • Beatriz Guitton Renaud Baptista de Oliveira ${ }^{6}$
}

\begin{abstract}
RESUMO
Objetivo: Analisar evidências científicas sobre as apresentações farmacêuticas e os efeitos antimicrobianos do fator de crescimento epidérmico recombinante humano em feridas. Método: Revisão integrativa de literatura, nas bases de dados contidas no portal Biblioteca Virtual em Saúde e no Portal de Periódicos da Coordenação de Aperfeiçoamento de Pessoal de Nível Superior, com os termos úlcera varicosa, úlcera cutânea, úlcera da perna, infecção dos ferimentos e fator de crescimento epidérmico. Foram incluídos estudos experimentais ou quase-experimentais que abordassem como tema central avaliações da efetividade do fator de crescimento epidérmico no reparo tecidual de feridas. Foram utilizadas as recomendações CONSORT como indicador de qualidade metodológica dos artigos. Resultados: Foram incluídos sete estudos, avaliados a partir das categorias: apresentações farmacêuticas de fator de crescimento epidérmico recombinante humano e seus efeitos no processo de reparo tecidual de lesões e emprego de terapia antimicrobiana como coadjuvante no tratamento de feridas com fator de crescimento epidérmico recombinante humano. Os estudos apontaram para o uso coadjuvante de fator de crescimento epidérmico com antimicrobianos. Conclusão: Os estudos avaliados não apontaram para a presença de atividades antimicrobianas do fator de crescimento epidérmico recombinante.
\end{abstract}

Palavras-chave: Enfermagem; Fator de crescimento epidérmico; Úlcera varicosa; Úlcera da perna; Infecção dos ferimentos.

\section{ABSTRACT}

Objective: To analyze scientific evidence about pharmaceutical forms and antimicrobial effects of recombinant human epidermal growth factor in wounds. Method: Integrative review, in databases contained on the website Virtual Health Library and Journals of Higher Education Personnel Improvement Coordination, with key words varicose ulcer, skin ulcer, leg ulcer, wound infection and epidermal growth factor. Experimental or quasiexperimental researchs about assessments related with the effectiveness of the epidermal growth factor in wound healing were included. CONSORT recommendations were used to evaluate the methodological quality of studies. Results: We included seven studies evaluated from the categories: pharmaceutical forms of recombinant human epidermal growth factor and its effects on wound healing process and employment antimicrobial therapy as an adjunct in the treatment of wounds with recombinant human epidermal growth factor. Studies indicated that epidermal growth factor should be used with others antimicrobial agents to fight wound infections. Conclusion: Studies have not indicated the presence of antimicrobial activity in recombinant epidermal growth factor.

Keywords: Nursing; Epidermal growth factor; Venous ulcer; Leg ulcer; Wound infection.

\section{NOTA}

${ }^{1}$ Mestre em Ciências do Cuidado em Saúde pela Universidade Federal Fluminense (UFF). Enfermeira da Educação Permanente do Hospital Badim (Rio de Janeiro, RJ, Brasil). E-mail: fernandapessanh@hotmail.com

2 Doutora em Humanidades e Artes pela Universidade Nacional de Rosário (Argentina). Professora Adjunta 2 do Departamento de Fundamentos de Enfermagem e Administração (MFE) da Universidade Federal Fluminense (UFF) (Niterói, RJ, Brasil). E-mail: miriammarinho@hotmail.com

${ }^{3}$ Mestre em Ciências do Cuidado em Saúde pela Universidade Federal Fluminense (UFF). Professora Auxiliar I do Departamento de Fundamentos de Enfermagem e Administração (MFE) da Universidade Federal Fluminense (UFF) (Niterói, RJ, Brasil). E-mail: bruna.barreto07@gmail.com

${ }^{4}$ Doutora em Enfermagem pela Universidade do Estado do Rio de Janeiro (UERJ). Professora Adjunta do Departamento de Fundamentos de Enfermagem e Administração (MFE) da Universidade Federal Fluminense (UFF) (Niterói, RJ, Brasil).E-mail: euzeli@terra.com.br

${ }_{5}^{5}$ Doutora em Enfermagem pela Universidade Federal do Rio de Janeiro (UFRJ). Professora Associada do Departamento de Fundamentos de Enfermagem e Administração (MFE) da Universidade Federal Fluminense (UFF) (Niterói, RJ, Brasil). E-mail: karinebrum @yahoo.com.br

${ }^{6}$ Doutorado em Enfermagem pela Universidade Federal do Rio de Janeiro (UFRJ). Professora Titular do Departamento de Fundamentos de Enfermagem e Administração (MFE) da Universidade Federal Fluminense (UFF) (Niterói, RJ, Brasil). E-mail: beatrizguitton@globo.com

Artigo extraído do Trabalho de Conclusão de Curso intitulado "Ação antimicrobiana do fator de crescimento epidérmico em feridas: Revisão Integrativa", da aluna Fernanda Pessanha de Oliveira, apresentado ao Curso de Especialização Lato-Sensu em Controle de Infecções relacionadas à Assistência à Saúde, da Escola de Enfermagem Aurora de Afonso Costa (EEAAC), da Universidade Federal Fluminense (UFF) (Niterói, RJ, Brasil) em fevereiro de 2016.

Não há conflitos de interesses por parte de nenhum dos autores deste trabalho.

Não houve nenhum financiamento de empresas ou de órgãos governamentais para o desenvolvimento desta pesquisa. Os investimentos realizados são de responsabilidade dos autores, como pessoas físicas. 


\section{INTRODUÇÃO}

Uma ferida é representada pela interrupção da continuidade de um tecido corpóreo, em maior ou em menor extensão, causada por qualquer tipo de trauma físico, químico, mecânico ou em decorrência de uma afecção clínica, que desencadeiam os mecanismos de defesa do indivíduo ${ }^{1}$.

O cuidado com feridas envolve medidas de prevenção de transmissão de infecções, que são de especial revelância ao se refletir sobre o impacto que as lesões, sobretudo crônicas ${ }^{2}$, geram na vida dos pacientes e também nos gastos advindos dos tratamentos, imputados aos sistemas de saúde.

Nos Estados Unidos, cerca de 6,5 milhões de pessoas sofrem com feridas crônicas, e cerca 25 bilhões de dólares são gastos anualmente para tratar complicações de saúde relacionadas às feridas ${ }^{3}$. No contexto do Brasil, essa realidade não é diferente. Embora dados brasileiros sejam pouco precisos, estima-se que quase $3 \%$ da população nacional são portadores de feridas crônicas, que se eleva para $10 \%$ nas pessoas com diabetes ${ }^{4}$.

Sabe-se que algumas feridas evoluem para o estado de cronicidade. Para o manejo de lesões crônicas, é preciso ter em vista que o processo de cicatrização pode ser influenciado por diversos fatores, os quais podem acelerar ou retardar a reparação tecidual, caso estejam relacionados adequadamente ou não. Dentre esses fatores, destaca-se a presença de infecção ${ }^{5}$.

O desenvolvimento de infecções em feridas crônicas pode determinar o prolongamento da fase inflamatória do processo de reparo tecidual. Por isso, considera-se que a diminuição da carga microbiana presente nas feridas crônicas a níveis inferiores aos característicos de infecção facilita o controle dos mediadores inflamatórios locais e sistêmicos ${ }^{6}$, reduzindo a inflamação.

Diferentes patógenos podem atuar determinando infecções em feridas crônicas. Destacam-se Staphylococcus aureus e Pseudomonas aeruginosa ${ }^{7-8}$, bem como Escherichia coli, Klebsiella pneumoniae, Proteus mirabilis, Citrobacter freundii e Estreptococos $\beta$-hemolíticos do grupo $B^{9}$.

Tendo esses fatores em vista, muitas vezes faz-se necessário o emprego de curativos com potencial para debelar infecções em feridas crônicas. Recentemente, inúmeras tecnologias têm sido desenvolvidas com esse objetivo.

Terapias a base de fator de crescimento epidérmico recombinante humano (rhEGF), também denominado sh-oligopeptídeo-1, são consideradas inovadoras no tratamento de feridas. Trata-se de um polipeptídeo de cadeia única, que tem um resíduo amino-terminal asparagina e um resíduo carboxilo- terminal arginina ${ }^{10}$, podendo ser obtido a partir de diferentes processos, dentre eles, a síntese por processos biotecnológicos, como a fermentação, através da bactéria E. coli. Seu mecanismo de ação envolve a atuação a nível celular através da interação com receptores EGF-R do tipo tirosina quinase, dando lugar a uma cascata de sinalização que resulta em uma sucessão de alterações bioquímicas, que determinam a regeneração tecidual ${ }^{11}$.

Vale salientar que diversos estudos envolvendo a utilização de biomateriais contendo rhEGF evidenciaram boa tolerabilidade e segurança com o uso continuado em seres humanos ou em animais experimentais ${ }^{12-16}$. Entretanto, não se sabe se o emprego desses biomateriais exerce alguma atividade antimicrobiana direta ou indiretamente.

Um estudo de revisão de literatura sugeriu que a combinação de apresentações farmacêuticas que envolvessem fatores de crescimento e antibióticos poderiam permitir uma terapia medicamentosa efetiva para a cicatrização de feridas crônicas ${ }^{17}$, indicando que os fatores de crescimento não apresentam tal efeito no reparo tecidual.

Portanto, as questões de pesquisa que orientaram esse estudo foram: Quais apresentações farmacêuticas empregadas e efeitos antimicrobianos foram observados no tratamento de feridas crônicas com fator de crescimento epidérmico recombinante humano (rhEGF)?

Assim, o objetivo deste estudo foi analisar evidências científicas sobre as apresentações farmacêuticas e os efeitos antimicrobianos do fator de crescimento epidérmico recombinante humano no tratamento de feridas.

Este estudo faz parte do grupo de pesquisa Gestão da Formação e Qualificação Profissional: Saúde e Educação, na linha de pesquisa Qualificação profissional e produção do conhecimento no controle de infecção na assistência à saúde, vinculado ao Núcleo de Estudos e Pesquisas em Cidadania e Gerência na Enfermagem (NECIGEN), do Departamento de Fundamentos de Enfermagem da Escola de Enfermagem Aurora de Afonso Costa da Universidade Federal Fluminense.

\section{MÉTODO}

Trata-se de uma revisão integrativa de literatura, considerada um método que tem como finalidade sintetizar resultados obtidos em pesquisas sobre um tema ou questão, de maneira sistemática, ordenada e abrangente. É denominada integrativa porque fornece informações mais amplas sobre um assunto/problema, constituindo, assim, um corpo de conhecimento ${ }^{18}$.

A revisão foi realizada a partir de levantamento bibliográfico eletrônico em todas as bases de dados contidas no portal Biblioteca Virtual em Saúde (BVS), bem como no Portal de Periódicos da Coordenação de Aperfeiçoamento de Pessoal de Nível Superior (CAPES), com a utilização de termos a partir das ferramentas Medical Subject Headings Section (MeSH), do PubMed/MEDLINE, e DeCS (Descritores em Ciências da Saúde), do Portal BVS: úlcera varicosa 
(varicose ulcer), úlcera cutânea (skin ulcer), úlcera da perna (leg ulcer), infecção dos ferimentos (wound infection), fator de crescimento epidérmico (epidermal growth factor).

Cabe destacar que por meio da BVS é possível realizar busca nas bases Literatura Latino-americana e do Caribe em Ciências da Saúde (LILACS), Índice Bibliográfico Espanhol de Ciências da Saúde (IBECS), Literatura Internacional em Ciências da Saúde (MEDLINE) e Scientific Electronic Library Online (SciELO).

Os critérios de inclusão foram estudos experimentais ou quase-experimentais que abordassem como tema central avaliações da efetividade do fator de crescimento epidérmico no reparo tecidual de feridas; estudos cuja coleta de dados se deu em qualquer nível de atenção à saúde, em português, inglês e espanhol, de qualquer ano de publicação, disponíveis gratuitamente online. Foram excluídos estudos com populações não humanas e textos repetidos nas diferentes bases de dados avaliadas. Empregou-se o operador boleano AND.

A pesquisa foi realizada entre os dias 22 e 30 de janeiro de 2016. Inicialmente, os textos tiveram seus títulos e resumos avaliados quanto à adequação ao tema proposto e aos demais critérios de inclusão. Posteriormente, os artigos incluídos na pesquisa tiveram seus textos completos lidos, em busca de evidências a respeito de potenciais efeitos antimicrobianos do fator de crescimento epidérmico quando aplicado em feridas. Dessa forma, foram incluídos quatro artigos a partir das buscas na BVS (Figura 1) e dois artigos a partir das buscas no Portal de Periódicos da CAPES (Figura 2), totalizando seis artigos.

Foram utilizadas as recomendações CONSORT (Consolidated Standards of Reporting Trials) como indicador de qualidade metodológica dos artigos ${ }^{19}$. Com base nas recomendações do CONSORT, os artigos foram classificados em três categorias: A - nos casos dos estudos preencherem valor igual ou maior que $80 \%$ dos critérios; B - nos casos de cumprimento entre 80 e $50 \%$ dos critérios estabelecidos e C - se houve cumprimento inferior a $50 \%$ dos critérios estabelecidos pelo CONSORT ${ }^{8}$.

\section{RESULTADOS}

Após a seleção e a leitura analítica dos artigos, foi organizado o quadro 1 , com os principais dados de cada pesquisa: ano, país, método do estudo, tipo de ferida, apresentação do fator de crescimento epidérmico (rhEGF), aspectos relacionados à microbiologia das lesões avaliadas e classificação segundo recomendações CONSORT.

Os resultados das buscas permitiram a seleção de seis artigos: dois ensaios clínicos randomizados duplo-cegos (28,57\%), um ensaio clínico não randomizado $(14,28 \%)$ e três estudos quase-experimentais (42,85\%).

Quatro artigos $(57,13 \%)$ tratavam de úlceras de pé diabético, um (14,28\%) de feridas de etiologia venosa e um $(14,28 \%)$ de lesões oncológicas e venosas.

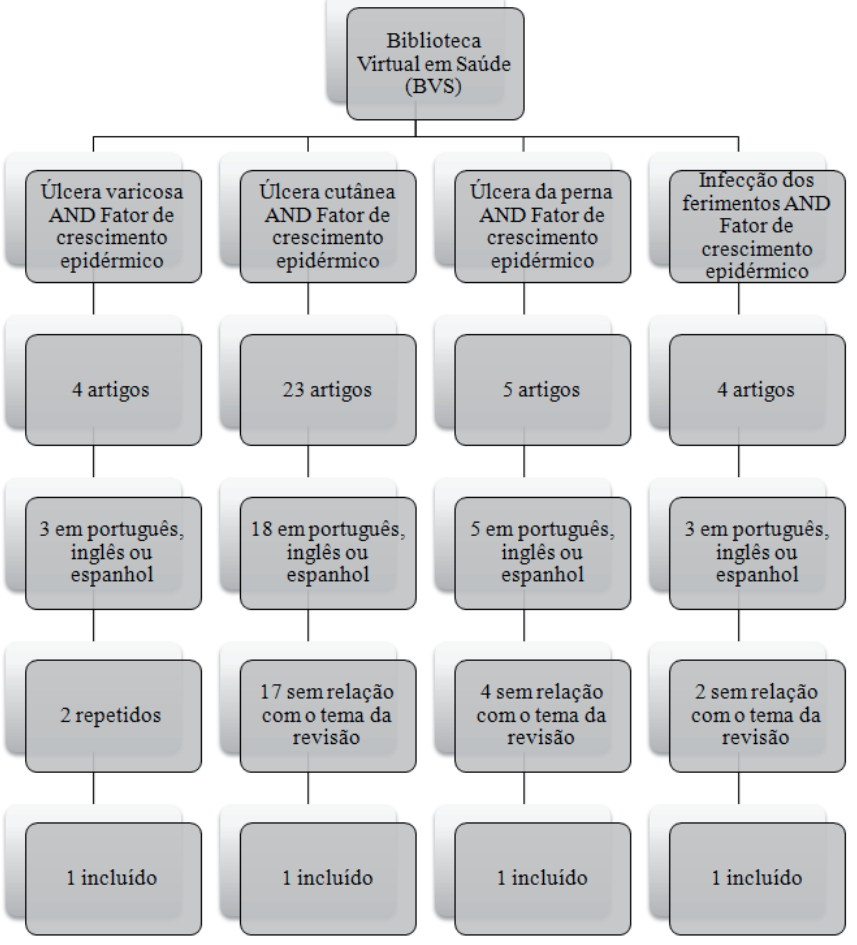

Figura 1 - Fluxograma de busca de artigos na Biblioteca Virtual em Saúde. Niterói, 2016

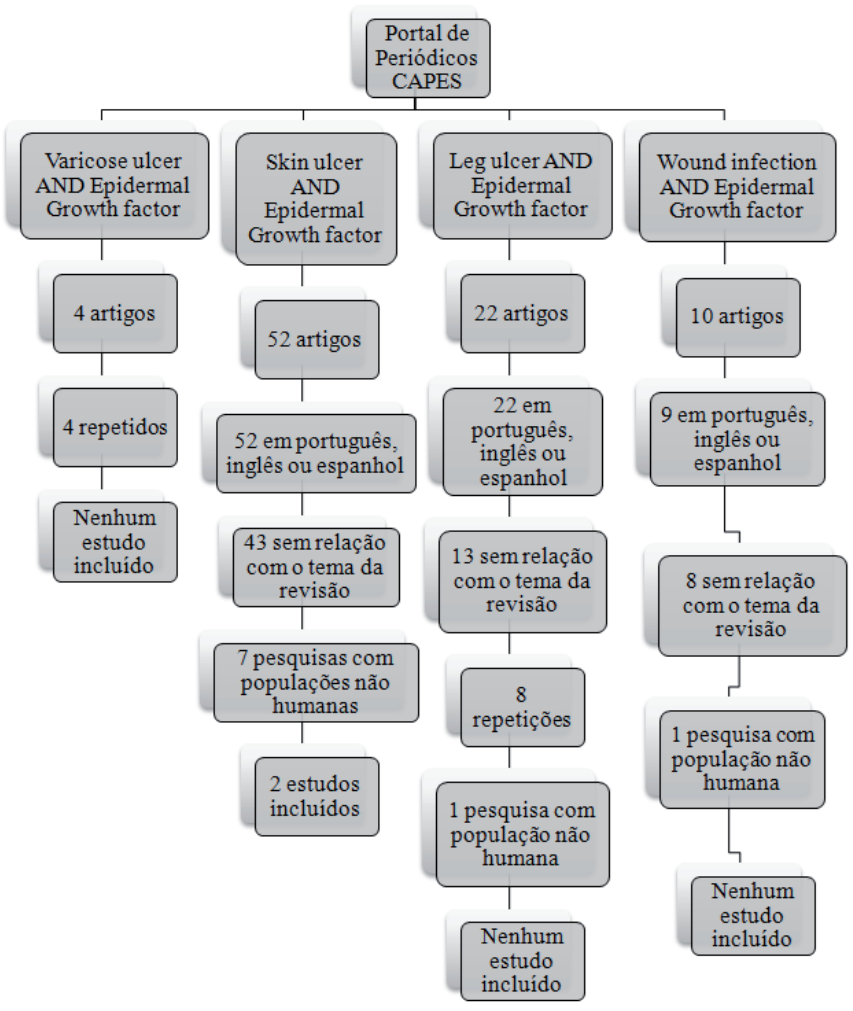

Figura 2 - Fluxograma de busca de artigos no Portal de Periódicos da CAPES. Niterói, 2016

Três estudos (42,85\%) envolveram a aplicação tópica de diferentes apresentações de rhEGF e três $(42,85 \%)$ abordaram a aplicação peri e intralesional de rhEGF, com destaque para o produto Heberprot- $\mathrm{P}^{\circledR}$. 
Quadro 1- Publicações incluídas na revisão integrativa da literatura por país de realização do estudo, autores, ano, periódico, área de atuação dos autores e tipo de estudo. Brasil, 2014

\begin{tabular}{|c|c|c|c|c|c|c|}
\hline Ano/ País & Método & $\begin{array}{l}\text { Tipo de } \\
\text { ferida }\end{array}$ & $\begin{array}{l}\text { Apresentação } \\
\text { do rhEGF }\end{array}$ & Objetivo do estudo & $\begin{array}{l}\text { Principais resultados e aspectos relacionados à } \\
\text { microbiologia das lesões }\end{array}$ & CONSORT \\
\hline $\begin{array}{l}\text { 2014/ } \\
\text { México }\end{array}$ & $\begin{array}{c}\text { Ensaio clínico } \\
\text { randomizado } \\
\text { duplo-cego. }\end{array}$ & $\begin{array}{l}\text { Úlceras } \\
\text { de pé } \\
\text { diabético. }\end{array}$ & $\begin{array}{c}\text { Pó liofilizado } \\
\text { Heberprot-P® } \\
(75 \mu \mathrm{g}) .\end{array}$ & $\begin{array}{l}\text { Determinar a } \\
\text { eficácia e a } \\
\text { segurança de rhEGF } \\
\text { em pacientes com } \\
\text { úlceras de pé } \\
\text { diabético. }\end{array}$ & $\begin{array}{l}\text { Foram incluídos } 34 \text { pacientes no estudo, dos quais } 15 \text { foram } \\
\text { randomizados para o grupo intervenção. Verificou-se que } \\
\text { mais úlceras alcançaram cicatrização completa, obtiveram } \\
\text { redução de área e desenvolveram ilhas de epitelização no } \\
\text { grupo intervenção, com significância estatística. } \\
\text { O desenvolvimento de infecção severa foi um dos critérios } \\
\text { de descontinuidade do estudo. Pacientes que desenvolveram } \\
\text { infecção superficial foram tratados com antibioticoterapia. } \\
\text { Após a injeção peri e intralesional de rhEGF, as feridas foram } \\
\text { cobertas com curativo primário a base de prata iônica. }\end{array}$ & A \\
\hline $\begin{array}{l}\text { 2012/ } \\
\text { Argentina }\end{array}$ & $\begin{array}{l}\text { Estudo quase } \\
\text { experimental. }\end{array}$ & $\begin{array}{l}\text { Úlceras } \\
\text { de pé } \\
\text { diabético. }\end{array}$ & $\begin{array}{c}\text { Pó liofilizado } \\
\text { Heberprot-P® } \\
\text { (75 } \mu \mathrm{g}) .\end{array}$ & $\begin{array}{l}\text { Avaliar os resultados } \\
\text { do tratamento das } \\
\text { úlceras severas } \\
\text { de pé diabético } \\
\text { (Wagner } 3 \text {-4) com } \\
\text { fator de crescimento } \\
\text { epidérmico } \\
\text { (Heberprot-P®) } \\
\text { utilizado na prática } \\
\text { médica habitual. }\end{array}$ & $\begin{array}{l}\text { Foram analisados } 124 \text { pacientes, dos quais } 91 \% \text { dos } \\
\text { pacientes apresentou resposta de granulação parcial. A taxa } \\
\text { de resposta de granulação total obtida foi de } 70,3 \% \text {, com } \\
\text { uma taxa de fechamento total das úlceras em } 69,2 \% \text { dos } \\
\text { pacientes. } \\
\text { Os pacientes com sinais de infecção na ferida receberam } \\
\text { antibioticoterapia. Dois pacientes desenvolveram infecção } \\
\text { nos membros inferiores durante o tratamento, recebendo } \\
\text { antibioticoterapia. }\end{array}$ & B \\
\hline $\begin{array}{l}2009 / \\
\text { Vietnã }\end{array}$ & $\begin{array}{l}\text { Estudo piloto } \\
\text { quase } \\
\text { experimental }\end{array}$ & $\begin{array}{c}\text { Úlceras } \\
\text { de pé } \\
\text { diabético. }\end{array}$ & $\begin{array}{l}\text { Spray Easyef } \\
\text { Saesa } \\
\text { Ointment }{ }^{\circledR}, \\
\text { (1ml de rhEGF } \\
\text { a concentração } \\
\text { de } 0,005 \% \\
\text { e } 9 \mathrm{ml} \text { de } \\
\text { um solvente } \\
\text { composto por } \\
20 \text { mg de metil- } \\
\text { parahidroxi- } \\
\text { benzoato). }\end{array}$ & \begin{tabular}{|} 
Avaliar a eficácia e a \\
segurança do rhEGF \\
na cicatrização de \\
úlceras de pé um \\
pacientes diabéticos.
\end{tabular} & $\begin{array}{l}\text { Foram avaliados no estudo } 28 \text { pacientes. Todos alcançaram } \\
\text { granulação das lesões. Verificou-se cicatrização completa } \\
\text { em } 56,5 \% \text { dos pacientes. Não foram observadas reações } \\
\text { alérgicas. } \\
\text { Foram feitas culturas microbiológicas das feridas no } \\
\text { momento do recrutamento para inclusão no estudo, mas não } \\
\text { são fornecidos dados sobre que tipos de testes eram feitos. } \\
\text { Das } 28 \text { feridas avaliadas, } 22 \text { tiveram culturas microbiológicas } \\
\text { positivas. O desenvolvimento de infecção na ferida durante o } \\
\text { estudo levou a exclusão do paciente da pesquisa. As feridas } \\
\text { passaram a receber o tratamento com Easyef e hidrocolóide } \\
\text { a partir do momento que eram consideradas limpas ou sem } \\
\text { infecção. }\end{array}$ & B \\
\hline $\begin{array}{l}1992 / \\
\text { Venezuela }\end{array}$ & $\begin{array}{c}\text { Ensaio clínico } \\
\text { randomizado } \\
\text { duplo-cego. }\end{array}$ & $\begin{array}{l}\text { Úlceras de } \\
\text { etiologia } \\
\text { venosa. }\end{array}$ & $\begin{array}{c}\text { Creme de } \\
\text { sulfadiazina } \\
\text { de prata } 1 \% \\
(10 \mu \mathrm{g} \text { de rhEGF } \\
\text { a cada } 1 \mathrm{~g} \text { de } \\
\text { creme) em } \\
\text { frascos de } 60 \mathrm{~g} .\end{array}$ & \begin{tabular}{|} 
Determinar o efeito \\
cicatrizante de \\
EGF associado com \\
sulfadiazina de \\
prata $1 \%$ comparada \\
com sulfadiazina de \\
prata isolada nas \\
lesões ulcerosas de \\
membros inferiores. \\
\end{tabular} & $\begin{array}{l}\text { Foram avaliados no estudo } 18 \text { pacientes, dos quais nove } \\
\text { estavam no grupo intervenção. Houve redução de mais de } \\
75 \% \text { de área das úlceras em } 30 \% \text { dos pacientes tratados } \\
\text { com sulfadiazina de prata com EGF. Já no grupo tratado } \\
\text { apenas com sulfadiazina de prata, nenhum dos pacientes } \\
\text { teve redução de área da ferida maior que } 75 \% \text {. Apesar disso, } \\
\text { não houve significância estatística. } \\
\text { Os pacientes foram submetidos a estudos bacteriológicos } \\
\text { do exsudato das feridas. Os resultados apontaram presença } \\
\text { de Pseudomonas aeruginosa e Staphylococcus aureus, } \\
\text { mas os autores não relatam se os pacientes foram ou não } \\
\text { submetidos à antibioticoterapia. }\end{array}$ & B \\
\hline $\begin{array}{l}\text { 2009/ } \\
\text { Venezuela }\end{array}$ & $\begin{array}{l}\text { Estudo quase } \\
\text { experi-mental. }\end{array}$ & $\begin{array}{c}\text { Úlceras } \\
\text { de pé } \\
\text { diabético. }\end{array}$ & $\begin{array}{l}\text { Pó liofilizado } \\
\text { Heberprot-P® } \\
\text { (doses de } \\
0.075 \mu \mathrm{g})\end{array}$ & $\begin{array}{l}\text { Identificar e } \\
\text { conhecer os } \\
\text { resultados obtidos } \\
\text { na aplicação de } \\
\text { doses indicadas de } \\
\text { Heberprot-P®, em } \\
\text { pacientes portadores } \\
\text { de lesões avançadas } \\
\text { grau } 5 \text { da escala de } \\
\text { Wagner, com ou sem } \\
\text { grau de isquemia } \\
\text { associado, e para } \\
\text { os quais tenha } \\
\text { sido considerada } \\
\text { a amputação da } \\
\text { extremidade. }\end{array}$ & $\begin{array}{l}\text { Foram incluídos no estudo } 70 \text { pacientes, tendo sido } \\
\text { evitada a amputação da extremidade em } 72,8 \% \text { dos casos. } \\
\text { Alcançaram a cicatrização total da ferida } 40 \% \text { dos pacientes. } \\
\text { Os pacientes utilizaram antibióticos, quando se verificou } \\
\text { essa necessidade. Foram utilizadas soluções antissépticas } \\
\text { durante a realização dos curativos. Todas as feridas tinham } \\
\text { algum grau de infecção local associado, achado esse, obtido } \\
\text { a partir da realização de culturas microbiológicas. }\end{array}$ & $\mathrm{C}$ \\
\hline 1989/Cuba & $\begin{array}{l}\text { Estudo piloto } \\
\text { experimental. }\end{array}$ & $\begin{array}{l}\text { Feridas } \\
\text { oncoló- } \\
\text { gicas e de } \\
\text { etiologia } \\
\text { venosa. }\end{array}$ & $\begin{array}{c}\text { Creme de } \\
\text { sulfadiazina } \\
\text { de prata } 1 \% \\
(10 \mu \mathrm{g} \text { de rhEGF } \\
\text { a cada } 1 \mathrm{~g} \text { de } \\
\text { creme }) .\end{array}$ & $\begin{array}{l}\text { Avaliar o efeito } \\
\text { terapêutico } \\
\text { cicatrizante da } \\
\text { aplicação tópica } \\
\text { de rhEGF em } \\
\text { úlceras cutâneas } \\
\text { de pacientes } \\
\text { oncológicos. }\end{array}$ & $\begin{array}{l}\text { Foram avaliados oito pacientes. Em } 50 \% \text { dos casos, } \\
\text { alcançou-se remissão completa das lesões. } \\
\text { Os autores não relataram aspectos relacionados à } \\
\text { microbiologia das feridas. }\end{array}$ & $\mathrm{C}$ \\
\hline
\end{tabular}


As avaliações, a partir das recomendações CONSORT, permitiram classificar um estudo no nível A (14,28\%), no qual se enquadram estudos de elevada qualidade metodológica; três estudos no nível B $(42,85 \%)$ e dois estudos como nível C (28,56\%).

\section{DISCUSSÃO}

Os resultados da presente pesquisa foram organizados em duas categorias para discussão: "Apresentações farmacêuticas do fator de crescimento epidérmico (rhEGF)" e "Aspectos relacionados à microbiologia das lesões tratadas com rhEGF".

\section{Categoria 1: Apresentações farmacêuticas do fator de crescimento epidérmico recombinante humano (rhEGF) e seus efeitos no processo de reparo tecidual de lesões}

Dos estudos incluídos na pesquisa, 33,33\% (2/6), descreveram o uso de cremes de sulfadiazina de prata $1 \%$ acrescido de rhEGF ${ }^{20-21} ; 50 \%$ (3/6) tratavam com produto Heberprot- $\mathrm{P}^{\oplus}$, desenvolvido para aplicação intra e perilesional ${ }^{22-24}$ e $16,66 \%(1 / 6)$ tratou com produto Easyef ${ }^{\oplus}$, um spray contendo rhEGF ${ }^{13}$.

No estudo realizado em 1992, na Venezuela ${ }^{20}$, foram realizados curativos com creme de sulfadiazina de prata contendo rhEGF em dez pacientes com úlceras venosas, cujos resultados de cicatrização foram comparados a dez pacientes com feridas tratadas unicamente com creme de sulfadiazina de prata.

O produto aplicado no grupo intervenção era composto por $10 \mu \mathrm{g}$ de rhEGF em cada $1 \mathrm{~g}$ de creme de sulfadiazina de prata. Os autores informaram que os percentuais de redução das úlceras tratadas com rhEGF foram maiores do que daquelas tratadas apenas com creme de sulfadiazina de prata, mas não houve significância estatística, o que é atribuído à amostra pequena ${ }^{20}$. Porém, outras avaliações quanto à estabilidade do produto não foram descritas, indicando que esse ponto pode ser um viés da pesquisa.

Na publicação de resultados preliminares de um estudo quase-experimental, que também aplicou topicamente rhEGF associado a creme de sulfadiazina de prata, realizado em Cuba ${ }^{21}$,os autores também não descreveram a realização de avaliações em relação à estabilidade do produto aplicado. Foram avaliados oito pacientes. Desses, dois apresentavam úlceras radiogênicas, os quais alcançaram $100 \%$ e $70 \%$ de cicatrização de seus leitos lesionais. Cinco pacientes tinham úlceras derivadas de extravasamento de citostáticos, dos quais, três apresentaram respostas parciais de cicatrização e dois tiveram completa reepitelização. Por fim, um paciente tinha uma úlcera venosa e também alcançou $100 \%$ de epitelização. Vê-se, com isso, que em 57,14\% dos pacientes obteve-se cicatrização completa.

Outra apresentação tópica, disponível na Coréia, China e em alguns países da América do Sul, avaliada em um dos estudos incluídos nessa revisão foi o Easyef Saesa Ointment ${ }^{\circledR}$, produzido por Daewoong Pharmaceutical Co., Ltd. (Coréia). É um produto em spray, contendo, $1 \mathrm{ml}$ de rhEGF a $0,005 \%$ e $9 \mathrm{ml}$ de um solvente composto por $20 \mathrm{mg}$ de metil-parahidroxibenzoato ${ }^{13}$. Avaliou-se a cicatrização de úlceras de pé diabético de 28 pacientes. Todas as lesões incluídas nesse estudo quase-experimental alcançaram $100 \%$ de cicatrização.

Por sua vez, Heberprot- ${ }^{\circledR}$, um produto inovador contendo fator de crescimento epidérmico recombinante humano para infiltração peri e intralesional, na forma de pó liofilizado, foi desenvolvido em Cuba. Seu registro foi feito em 2006 e, em 2007, foi incluído na Lista Nacional Cubana de Medicamentos Básicos, sendo aprovado para comercialização.

No ensaio clínico controlado randomizado duplo-cego realizado em 2014, no México ${ }^{22}$, a eficácia e a segurança da aplicação intra e perilesional desse produto três vezes por semana foi avaliada em comparação com a aplicação de um veículo (placebo) em clientes com úlceras de pé diabético durante oito semanas. Foram incluídos 34 pacientes, tendo ocorrido diferenças significativamente estatísticas no grupo intervenção quando comparado ao grupo controle, destacando-se os desfechos: cicatrização completa das úlceras, tendo ocorrido em quatro casos no grupo intervenção e em nenhum no grupo controle $(p=$ 0,033); diminuição das áreas das feridas, de cerca de 12,5 $\mathrm{cm}^{2}$ no grupo intervenção e $5,2 \mathrm{~cm}^{2}$ no controle $(p=0,049)$; e formação de ilhas de epitelização no leito das lesões, que ocorreu em $28 \%$ dos casos no grupo intervenção e em $3 \%$ no grupo controle $(p=0,025)$.

Já em um estudo quase-experimental desenvolvido na Argentina ${ }^{23}$, em 2012, avaliando o produto Heberprot-P ${ }^{\circledR}$ aplicado em 124 pacientes com úlceras diabéticas, verificou-se que $91 \%$ dos pacientes apresentaram resposta de granulação parcial, $70,3 \%$ teve suas lesões totalmente granuladas e $69,2 \%$ das lesões foram cicatrizadas. 0 tempo médio de cicatrização foi de 13 semanas.

Da mesma maneira, em outro estudo quaseexperimental ${ }^{24}$ foram avaliados 70 pacientes com úlceras severas de pé diabético tratadas com Heberprot- ${ }^{\circledR}{ }^{\circledR}$ em dias alternados. Dentre esses pacientes, as injeções intra e perilesionais conduziram a cicatrização completa em 28 casos (40\%).

\section{Categoria 2: Emprego de terapia antimicrobiana como coadjuvante no tratamento de feridas com fator de crescimento epidérmico recombinante humano (rhEGF)}

Dos seis estudos analisados, 50\% descreveram que pacientes com sinais de infecção nas lesões foram submetidos à antibioticoterapia ${ }^{22-24}$, pesquisas essas publicadas entre 2009 e 2014, o que pode indicar que a relevância deste aspecto nas avaliações das lesões vem sendo prioritariamente considerada mais recentemente. 
O estudo realizado em 1992, na Venezuela ${ }^{20}$, associou rhEGF à sulfadiazina de prata. É possível que alguma ação antimicrobiana tenha ocorrido devido à presença da prata, que tem ação bactericida. Os autores informam ter realizado estudos bacteriológicos a partir do exsudato das feridas avaliadas, tendo encontrado prioritariamente Pseudomonas aeruginosa $(64,7 \%)$ entre as bactérias gram-negativas e Staphylococcus aureus (35,29\%), entre as gram-positivas. Entretanto, não são encontradas no estudo associações entre os resultados das culturas microbiológicas e os resultados de cicatrização obtidos. Se fossem realizadas, essas avaliações teriam enriquecido significativamente o trabalho.

Da mesma forma, em um estudo preliminar ${ }^{21}$, no qual se verificou uma associação de rhEGF com sulfadiazina de prata, não foram descritos aspectos microbiológicos, nem mesmo quanto a conhecida atividade bactericida da prata.

Por outro lado, o estudo realizado no Vietnã ${ }^{13}$, em 2009, informou que as feridas apenas passaram a receber o curativo com Easyef Saesa Ointment ${ }^{\circledR}$ e uma cobertura secundária de hidrocolóide quando encontravam-se sem infecção. A presença de infecção na ferida na fase de recrutamento era um critério de exclusão, como o desenvolvimento de infecção na ferida durante o tempo de seguimento dos pacientes no estudo era um critério de descontinuidade. Assim, não foram feitas verificações relacionadas a potenciais ações antimicrobianas do rhEGF.

No estudo que avaliou o produto Heberprot- ${ }^{\circledR}$, no México, em 201422, os autores afirmaram que a aplicação tópica de rhEGF em feridas crônicas é desaconselhada, pois as proteases do biofilme que, em geral, cobrem essas lesões podem degradar o produto. Nesse sentido, apesar do estudo ter um desenho que reflete grande qualidade metodológica, cabe destacar que não foram feitas avaliações laboratoriais para comprovar essa afirmação.

Pacientes que desenvolveram infecção superficial nas feridas $^{22}$ foram tratados com antibioticoterapia, e aqueles que apresentaram infecções severas foram descontinuados da pesquisa, indicando que o rhEGF não tenha ação antimicrobiana. $O$ emprego de uma cobertura primária a base de prata iônica, após a injeção intra e perilesional de Heberprot- $\mathrm{P}^{\circledR}$, pode ter colaborado para o controle de infecções ${ }^{22}$.

Em outro estudo realizado na Argentina avaliando o Heberprot-P ${ }^{\circledR 23}$, considerou-se 0 desenvolvimento de infecção superficial nas feridas como evento adverso e os pacientes que enfrentaram esse circunstância receberam antibioticoterapia, corroborando ausência de ação antimicrobiana do rhEGF. Os autores não descreveram claramente qual via foi empregada para administração dos antimicrobianos, mas informaram que, nos casos em que esse tratamento foi necessário, os pacientes foram internados, dando a entender que os antimicrobianos foram administrados por via parenteral.

Da mesma forma, em pesquisa realizada em 200924, os autores informaram que os pacientes com infecção receberam antibioticoterapia e também não relataram claramente qual via foi empregada, registrando apenas que os pacientes foram internados para tratamento. Além disso, os curativos foram realizados com uso de soluções antissépticas. Verificou-se que havia contaminação microbiana em todas as lesões avaliadas por meio de culturas.

\section{CONCLUSÃO}

Considerando que, em geral, os artigos apontaram para o uso de medicações antimicrobianas nos casos em que as feridas apresentaram características de infecção, além do uso de fator de crescimento epidérmico recombinante humano (rhEGF), pode-se inferir que este produto não apresenta atividade antimicrobiana quando aplicado em feridas crônicas.

Sugere-se a realização de ensaios clínicos randomizados controlados com rigor metodológico, que avaliem a efetividade de diferentes apresentações de rhEGF, em diferentes tipos de lesões crônicas. Destaca-se, nesse sentido, a necessidade de uma assistência integral ao paciente, com a inclusão da realização de estudos observacionais que promovam avaliações microbiológicas com vistas a comparar as espécies bacterianas presentes tanto nas feridas tratadas com rhEGF, bem como naquelas tratadas com placebos ou terapias padrões.

\section{REFERÊNCIAS}

1. Brito KK et al. Feridas Crônicas: Abordagem da Enfermagem na produção científica da pós-graduação. Rev Enferm UFPE Online. 2013; 7(2):414-21.

2. Guo S, DiPietro LA. Factors Affecting Wound Healing. J Dent Res. 2010; 89(3): 219-29.

3. Wong VW, Gurtner GC. Tissue engineering for the management of chronic wounds: current concepts and future perspectives. Exp Dermatol. 2012; 21(10): 729-734.

4. Silva FAA et al. Enfermagem em estomaterapia: cuidados clínicos ao portador de úlcera venosa. Rev Bras Enferm. 2009; 62(6): 889-93.

5. Downe A. Use of Urgotul SSD ${ }^{\circledR}$ to reduce bacteria and promote healing in chronic wounds. $\mathrm{Br} J$ Community Nurs. 2013; Suppl:S32, S34-8.

6. Dhall $S$ et al. A novel model of chronic wounds: importance of redox imbalance and biofilm-forming bacteria for establishment of chronicity. PLoS One. 2014; 9(10): e109848.

7. Martins MA et al. Úlcera crônica de perna de pacientes em tratamento ambulatorial: análise microbiológica e de suscetibilidade antimicrobiana. Cienc Cuid Saude. 2010; 9(3):464-470.

8. Pessanha FS et al. Main microorganisms found and products used in contaminated tissular lesions: an integrative review. Online Braz J Nurs. 2015; 14(1):95-105.

9. Mihai MM et al. Identification and phenotypic characterization of the most frequent bacterial etiologies in chronic skin ulcers. Rom J Morphol Embryol. 2014; 55(4):1401-1408. 
10. Taylor JM, Mitchell WM, Conhen S. Epidermal Growth Factor: Physical and chemical properties. J Biol Chem. 1972; 247(18): 5928-5934.

11. Chan LK, Chiu YT, Sze KM, Ng IO. Tensin4 is up-regulated by EGF-induced ERK1/2 activity and promotes cell proliferation and migration in hepatocellular carcinoma. Oncotarget. 2015: 6(25): 20964-76.

12. Acosta JB et al. Epidermal Growth factor in clinical practice - A review of its biological action, clinical indications and safety implication. Int Wound J. 2009; 5(6): 331-46.

13. Tuyet HL et al. The efficacy and safety of epidermal growth factor in treatment of diabetic foot ulcers: the preliminary results. Int Wound J. 2009; 6(2): 159-66.

14. Choi JK et al. The effect of epidermal growth factor (EGF) conjugated with low-molecularweight protamine (LMWP) on wound healing of the skin. Biomaterials. 2012; 33(33): 8579-90.

15. Ruan RQ et al. et al. Transdermal delivery of human epidermal growth factor facilitated by a peptide chaperon. Eur J Med Chem. 2013; 62: 405-9.

16. Caussa JE, Vila EH. Epidermal growth factor, innovation and safety. Med Clin (Barc). 2014; 145(7): 305-12.

17. Hardwicke J, Schmaljohann D, Boyce D, Thomas D. Epidermal growth factor therapy and wound healing - past, present and future perspectives. Surgeon. 2008; 6(3): 172-7.

18. Ercole FF, Melo LS, Alcoforado CLGC. Revisão integrativa versus Revisão sistemática. Rev Min Enferm. 2014 jan/mar; 18(1):1-260.

19. Martins J, Sousa LM, Oliveira AS. Recomendações do enunciado CONSORT para o relato de estudos clínicos controlados e randomizados. Medicina (Ribeirão Preto). 2009; 42(1): 9-21.

20. Chirinos MER, Lugo AJR. Efecto del factor de crecimiento epidermico sobre las ulceras de miembros inferiores causadas por insuficiencia venosa. Dermatologia Venezolana. 1992: 30(1): 27-31.

21. Barroso MC et al. Efecto del factor de crecimiento epidérmico humano recombinante sobre úlceras cutâneas: reporte preliminar. Interferón Biotecnol. 1989; 6(1): 57-61.

22. Gomez-Villa R et al. Efficacy of intralesional recombinant human epidermal growth factor in diabetic foot ulcers in Mexican patients: A randomized double-blinded controlled trial. Wound Repair Regen. 2014; 22(4): 497-503.

23. Garelli G, Calvagno M, Tolstano A, Carrio M, Bulo F, Gómez R Tratamiento de úlceras severas de pié diabético con factor de crecimiento epidérmico recombinante (Heberprot- ${ }^{\circledR}$ ): Análisis retrospectivo de los resultados obtenidos en Argentina. Rev Argent Cir Cardiovasc (Impresa). 2012; 10(3): 153-62.

24. Montequin JF, Mena G, Santiesteban LB. El Heberprot-P® es una alternativa eficaz en el tratamiento del pie diabético grado 5 de la Clasificación de Wagner. Rev Esp Investig Quir. 2009; 12(4): 165-70. 